\title{
Preliminary study of colony type stability of Neisseria gonorrhoeae in liquid culture
}

\author{
A. E. JEPHCOT T * \\ Public Health Laboratory, Sheffield
}

Microbiological research frequently necessitates the production of large quantities of bacterial cells. These can most readily be obtained by liquid culture techniques. Such techniques also lend themselves well to vaccine production and isotope labelling procedures. If these methods are to be applied usefully to the gonococcus, then the colony type variations occurring in such systems must be known (Jephcott and Reyn, 1971).

Three liquid culture systems using gonococci of known colony type have been described:

(i) A rich non-defined single phase medium (Brooks and Hedén, 1967).

(ii) A defined single phase medium (Kenny, Ashton, Diena, and Greenberg, 1967).

(iii) A complex non-defined biphasic medium (Sparling, 1966).

All workers reported good yields and high stability of colony types, but as their studies were incomplete and as initial studies by the author did not always confirm their observations, an investigation of the problems was undertaken.

An attempt was made to define the degrees of multiplication, the ultimate yields, and colony type variations which could be expected under conventional culturing conditions, using three media similar to those referred to above. In addition, those conditions of inoculum size, $\mathrm{CO}_{2}$ tension, and temperature, which afford greatest stability of colony type whilst still permitting satisfactory multiplication, were sought.

\section{Material and methods}

MEDIA

(i) Nutrient broth (HYL) (Möller and Reyn, 1965) with 10 per cent. ascitic fluid. This was a complex nutrient medium known to give good growth of gonococci.

(ii) A completely defined medium (Kenny and others, 1967). This consisted of Medium 199 (Morgan, Morton, and Parker, 1950) supplemented with

Received for publication April 14, 1972

* Studies carried out during a visit to Copenhagen financed by a WHO Research Training Fellowship. dextrose, cocarboxylase, glutamine, and ferric chloride.

(iii) A biphasic system consisting of $100 \mathrm{ml}$. of a dextrose starch agar base (Difco) covered with a $25 \mathrm{ml}$. layer of dextrose starch peptone solution (Gerhardt and Hedén, 1960).

(iv) A solid medium described by Kellogg, Peacock, Deacon, Brown, and Pirkle (1963).

(v) Haemoglobin-yeast-liver agar with 6.7 per cent. horse blood replacing the haemoglobin (modified HYL) (Möller and Reyn, 1965).

GONOCOCCAL STRAINS

These were freshly isolated cultures including $82409 / \mathrm{SS}$ 1969 and old laboratory maintained cultures including F62 (Kellogg) and 43562/SS 1944.

\section{TECHNIQUE}

Volumes of $100 \mathrm{ml}$. of the liquid media or $100+25 \mathrm{ml}$. of the biphasic medium, in $250 \mathrm{ml}$. conical flasks, were inoculated with suspensions of gonococci from 18-hour plate cultures of known colony type in $0.1 \mathrm{ml}$. of Hanks's solution or ascitic broth. The atmosphere inside the flasks was washed out with 10 per cent. $\mathrm{CO}_{2}$ in air by bubbling this through the medium both before and after inoculation. The flasks were then sealed and incubated at $37^{\circ} \mathrm{C}$. in an orbital incubator set at 160 oscillations per minute.

Samples were removed at intervals and counts of colony-forming units (CFU) performed by plating dilutions onto Kellogg's and modified HYL media and/or by a loop plate dilution method using the same media. Good correlation was obtained between the two methods. The proportion of each colony type present at each count was assessed by examination of the Kellogg plates using an appropriate microscope (Jephcott and Reyn, 1971).

During experiments to compare the effects of different $\mathrm{CO}_{2}$ tensions, flasks closed loosely with gauze were incubated in a range of atmospheres within the orbital incubator.

\section{Results}

(1) Complex single-phase medium

TYPES 3 AND 4

Rapid abundant multiplication occurred from preincubation counts of $10^{5}$ or $10^{6} \mathrm{CFU} / \mathrm{ml}$. Peak 
counts of $10^{8}$ and $10^{9} \mathrm{CFU} / \mathrm{ml}$. were obtained within $10 \mathrm{hrs}$. No changes in type occurred (Fig. 1). The generation time was approximately $50 \mathrm{~min}$.

\section{TYPES 1 AND 2}

Initial concentrations of $10^{5}$ and $10^{6} \mathrm{CFU} / \mathrm{ml}$. gave rise to rapid multiplication, yielding counts of nearly $10^{8}$ in $10 \mathrm{hrs}$. However, within 4 hours colony type change occurred and thereafter Types 3 and 4 predominated. This change was most marked in the
Type 2 cultures. As the count fell again in the post $\log$ phase, the proportion of CFU of the original colony type became much larger again (Fig. 2).

\section{(2) Defined medium}

TYPES 3 AND 4

If a large inoculum of cells from Types 3 or 4 was used (giving an original count of $>10^{6} \mathrm{CFU} / \mathrm{ml}$., then an increase of about $10^{2}$-fold occurred within $24 \mathrm{hrs}$. Lag periods of up to $12 \mathrm{hrs}$ were observed

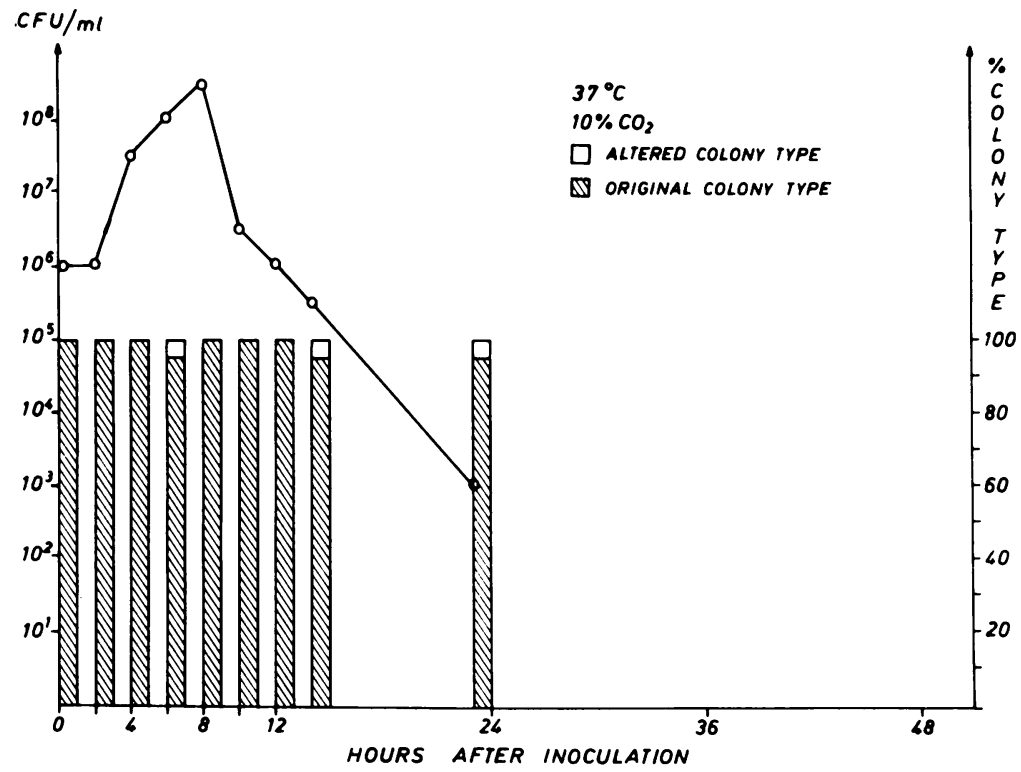

FIG. 1 Culture of cells from Type 4 colonies in ascitic broth

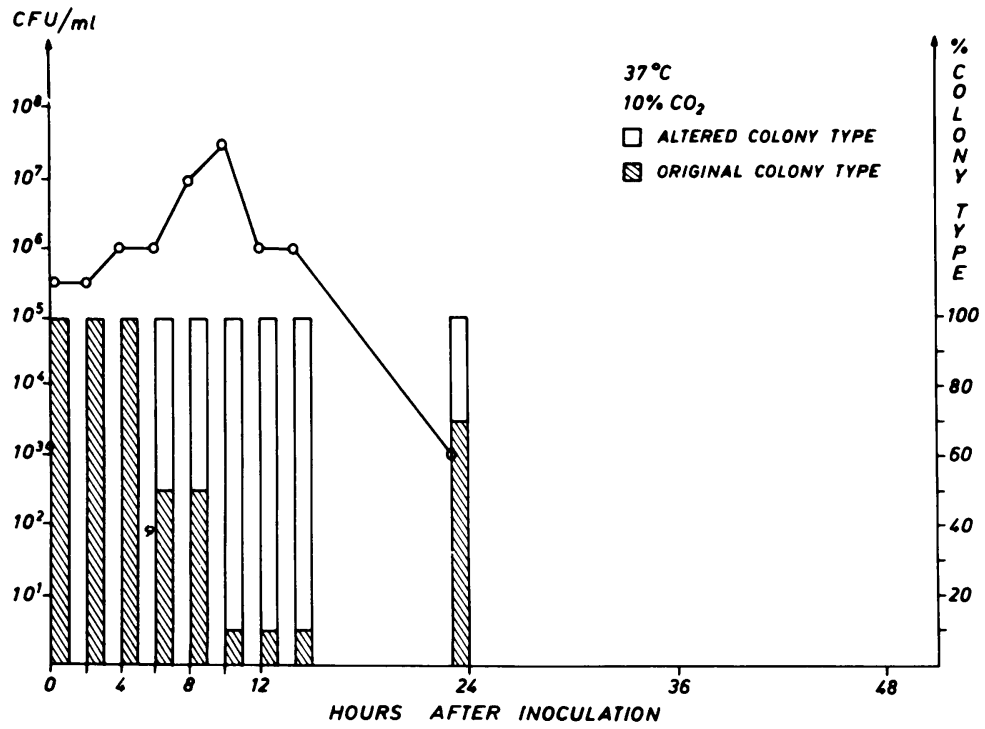

FIG. 2 Culture of cells from Type 2 colonies in ascitic broth 
and the generation time during the log phase was in the region of $100 \mathrm{~min}$.

If a smaller inoculum was employed (preincubation count of $\leq 10^{6} \mathrm{CFU} / \mathrm{ml}$.) then a prolonged lag phase of between 12 and $18 \mathrm{hrs}$ was observed, during which the count often fell. This was followed by a period of multiplication at the same rate as that which occurred with large inocula, and while the same final count was reached, a greater degree of multiplication had occurred to achieve this. Thus increases of up to $5 \times 10^{3}$-fold were encountered. One such growth curve is shown in Fig. 3. No reversions to Type 1 or 2 colonies were seen. Minor degrees of transition between Types 3 and 4 took place.

TYPES 1 AND 2

If the starting count was $10^{6} \mathrm{CFU} / \mathrm{ml}$. or fewer, then a prolonged lag phase of $12-24 \mathrm{hrs}$ was usually observed, after which a change in the colony type to Type 3 or 4 occurred. This was followed by the start of a multiplication phase which yielded counts of up to $10^{8} \mathrm{CFU} / \mathrm{ml}$. with a generation time of approximately $50 \mathrm{~min}$. (Fig. 4). If this change of type did not occur then the count fell slowly to zero.

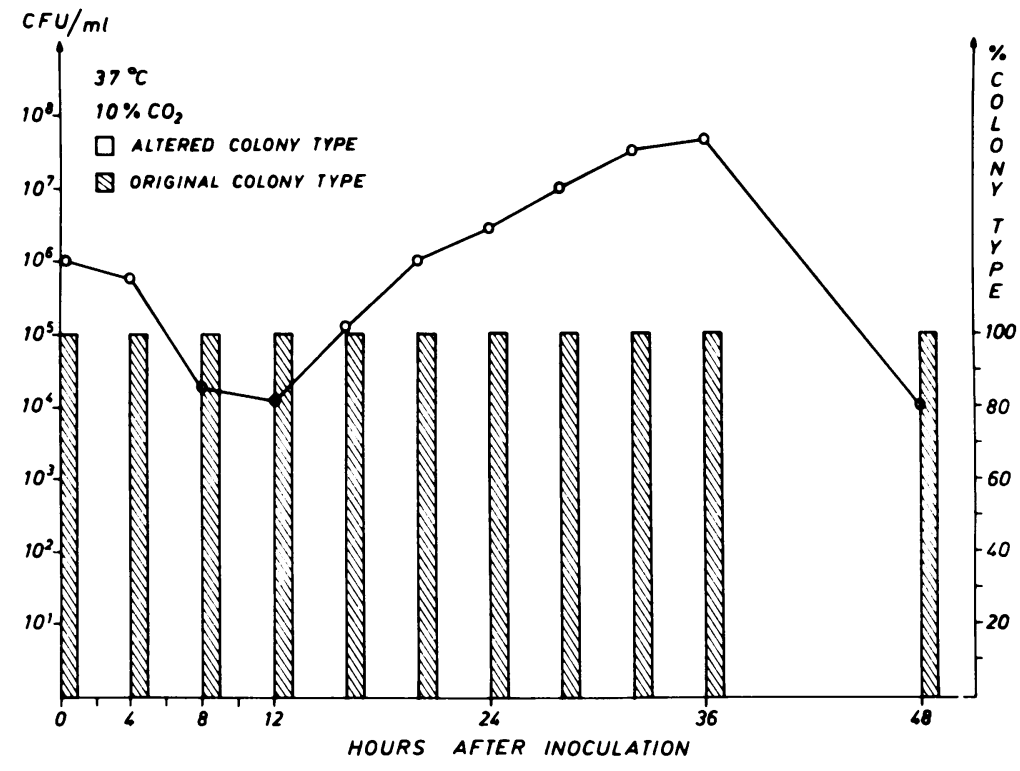

FIG. 3 Culture of cells from Type 4 colonies in defined medium

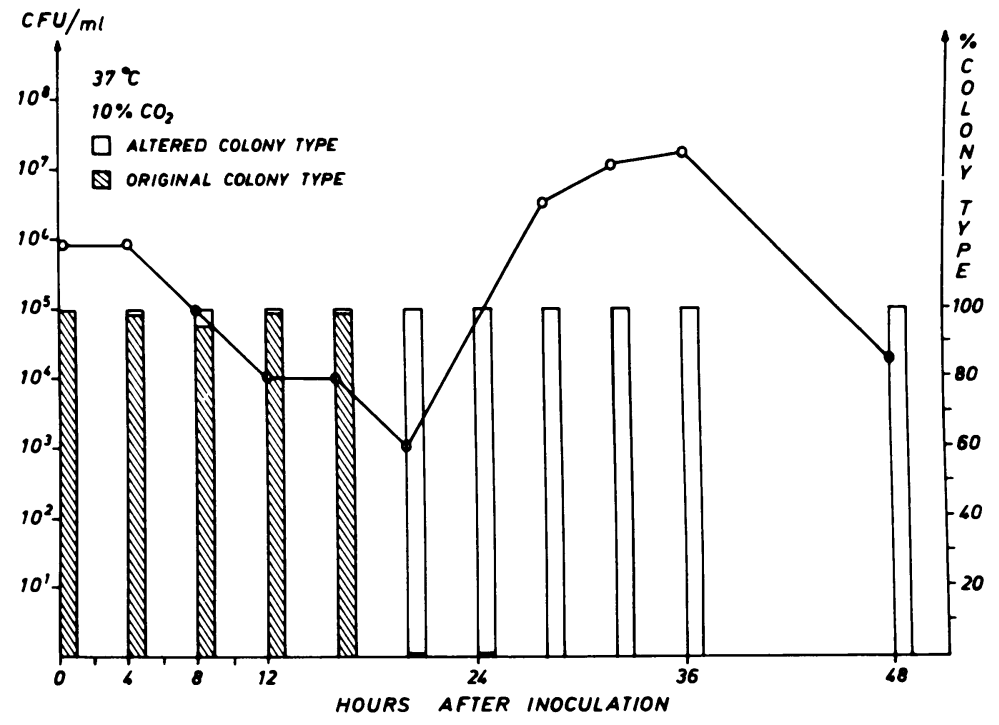

FI G. 4 Culture of cells from Type 1 colonies in defined medium. Smaller inoculum 
If larger inocula were used, giving initial counts of $>10^{6} \mathrm{CFU} / \mathrm{ml}$., then a slow rise in count started immediately. Increases of $10^{1}$ or $10^{1 \cdot 5}$-fold only were obtained, by which time in the case of all Type 2 cultures, and of most Type 1 cultures, the type had changed to a significant degree (Fig. 5). Generation times exceeded 2 hours. In occasional cultures of Type 1 cells the colony type remained stable and higher counts were obtained.

(3) Biphasic medium

Cultures in this medium remained with high CFU
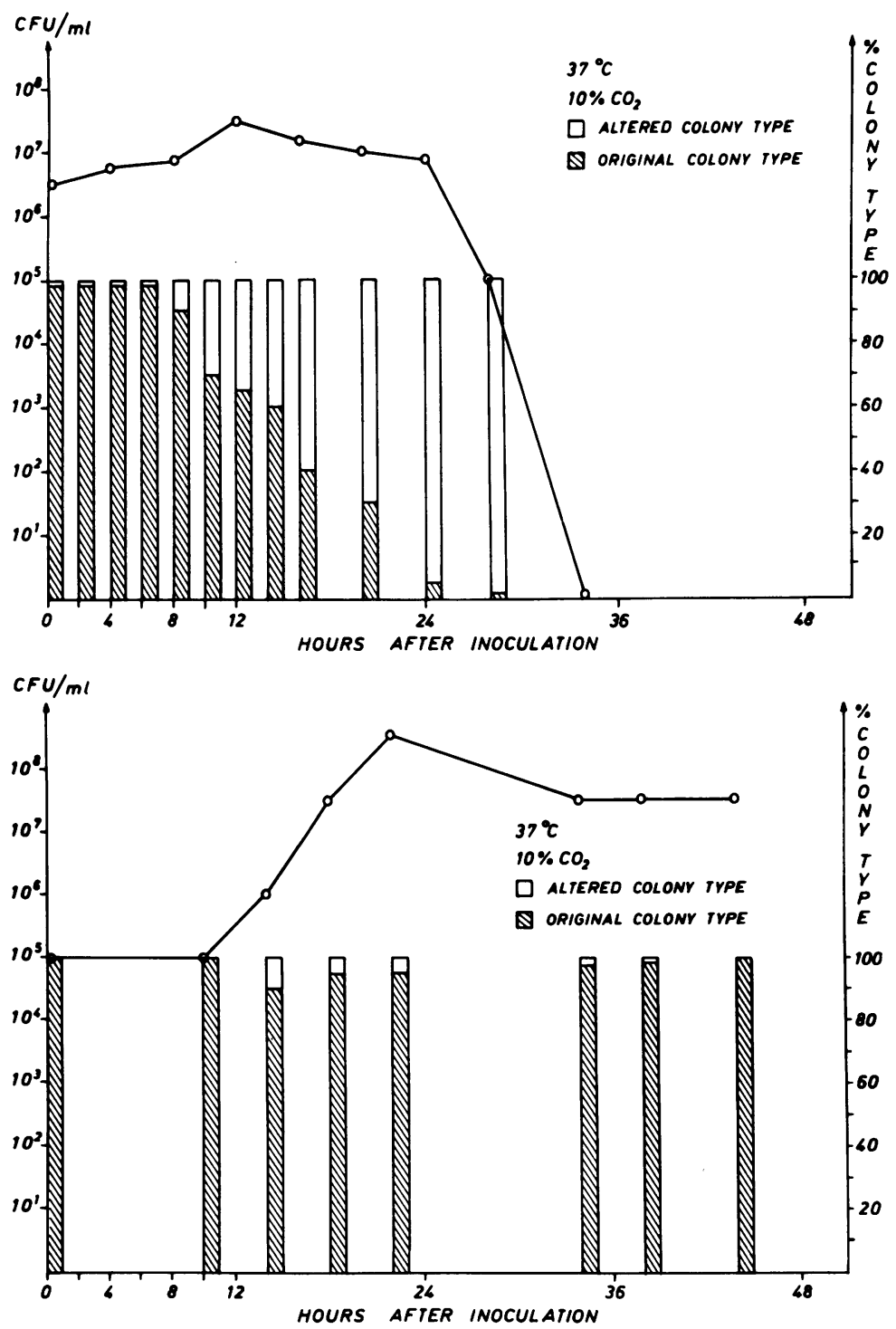

counts for at least $48 \mathrm{hrs}$. The results described below were obtained with the F62 strain. Certain other strains behaved similarly, but others grew more slowly and were not as stable.

TYPES 3 AND 4

Initial counts of $10^{4} \mathrm{CFU} / \mathrm{ml}$. or more, regularly produced peak counts of $10^{8.5}$ or $10^{9}$ within $24 \mathrm{hrs}$. Generation time approximated to $70 \mathrm{~min}$. No changes to Types 1 or 2 occurred (Fig. 6).

TYPES 1 AND 2

Starting counts of about $10^{5}$ increased to $10^{8}$ within
FIG. 5 Culture of cells from Type 1 colonies in defined medium. Larger inoculum
FIG. 6 Culture of cells from Type 4 colonies in biphasic medium 
$24 \mathrm{hrs}$ with comparatively little alteration in colony type. Generation time was in the region of $75 \mathrm{~min}$. and high counts were maintained for more than $40 \mathrm{hrs}$ (Fig. 7). Larger inocula accelerated the rate of colony type change without producing higher maximum counts. Type 2 cells showed a greater tendency to alter to other types than did Type 1 cells and they grew more slowly.

(4) Effect of $\mathrm{CO}_{2}$ tension variation in biphasic medium
Cells of all types of F62 grew well at between 1.2 and 10 per cent. $\mathrm{CO}_{2}$ and poorly at 30 per cent. $\mathrm{CO}_{2}$. At 10 and 15 per cent. $\mathrm{CO}_{2}$, they remained unaltered for 18-20 hrs. At low $\mathrm{CO}_{2}$ tensions, rapid change to Types 3 and 4 occurred (Fig. 8).

Strain 82409/SS 1969 grew well between $1 \cdot 2$ and 10 per cent. $\mathrm{CO}_{2}$ and poorly at 15 per cent. Cells from Types 1 and 2 were most stable at 10 per cent. $\mathrm{CO}_{2}$.

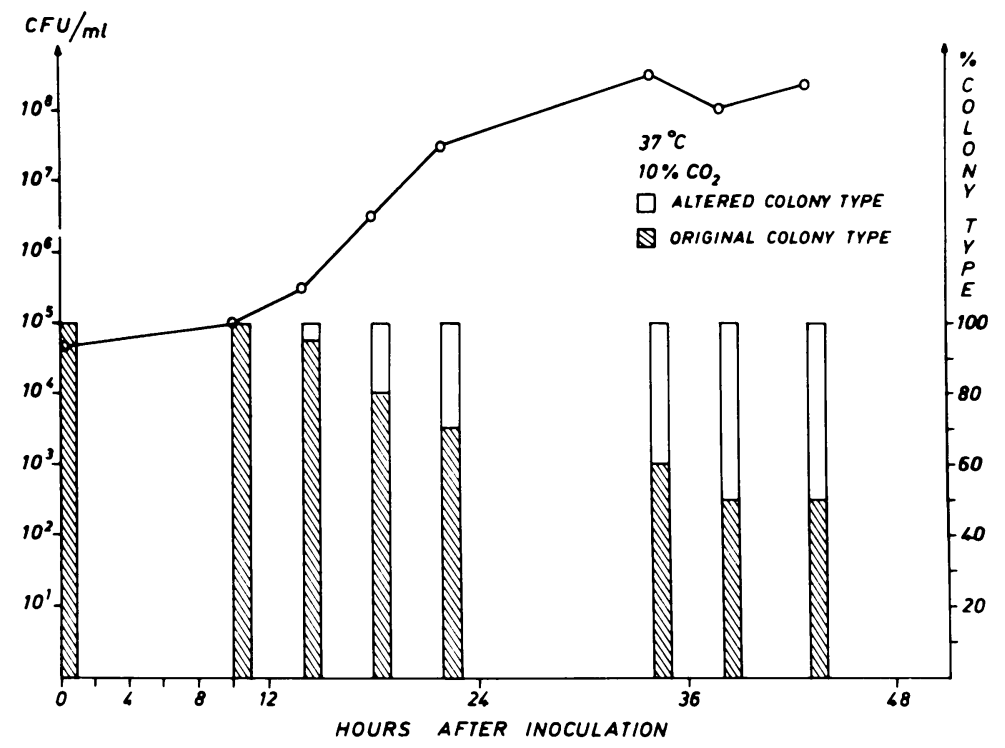

FIG. 7 Culture of cells from Type 1 colonies in biphasic medium at 10 per cent. $\mathrm{CO}_{2}$ tension

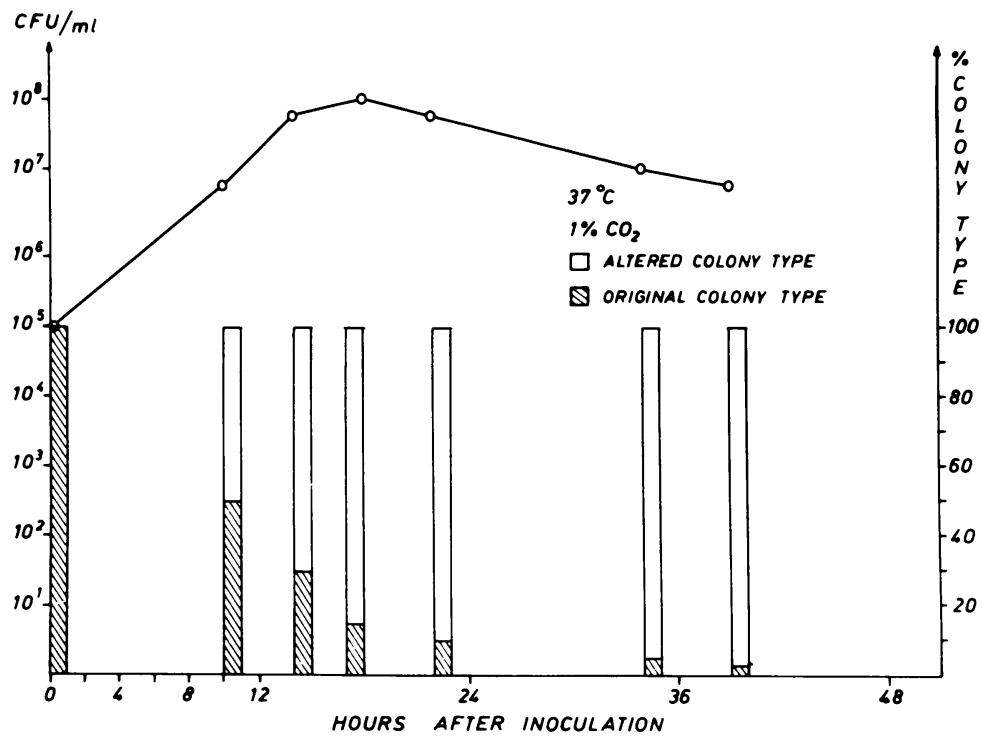

FI 8 Culture of cells from Type 1 colonies in biphasic medium at 1 per cent. $\mathrm{CO}_{2}$ tension 


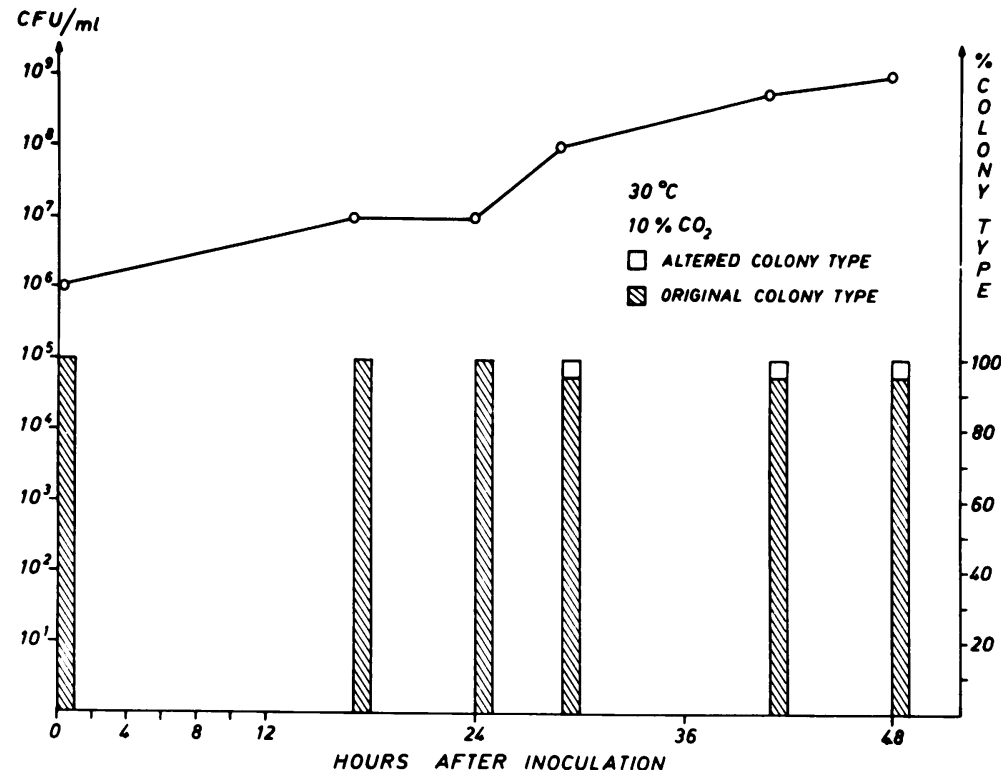

(5) Effect of incubation at $30^{\circ} \mathrm{C}$. in biphasic medium Growth was slow at this temperature with a generation time of 140-160 min. Type 1 cultures were unstable but Type 2 cultures did show steady increases in numbers over $48 \mathrm{hrs}$ with almost no alteration into other colony types (Fig. 9, above).

\section{Discussion}

The results described suggest differences in behaviour between the various cultures. They should be interpreted with caution, however, as gonococci have a great tendency to form clumps in liquid media. Despite vigorous agitation of all samples, the numbers of CFU counted could have been only approximate estimates of the actual numbers of bacteria contained. Nor was the degree of clumping always uniformcultures yielding Type 2, and to a lesser extent those yielding Type 3 colonies, contained larger aggregates than those yielding other types, with the smallest aggregates being found in type 4 yielding cultures. This may have led to some underestimation of the proportion of Type 2 producing cells.

Despite this difficulty the trends shown are sufficiently clear to allow valid conclusions:

\section{(1) Complex single-phase medium}

Media such as the one used are commonly employed for the culture of gonococci. Very good yields are obtainable with cells from Type 3 and 4 colonies. The generation time of $50 \mathrm{~min}$. agrees well with previous unpublished results obtained by Reyn (1971) and suggests that these organisms are 'adjusted' to growth in this medium. Cells from Type 1 and 2 colonies rapidly change type and no yield of these types can be expected.

There is some evidence for the persistence of part of the inoculum unchanged throughout the entire growth period, and it is tempting to speculate that the curves obtained represent a combination of survival of the Type 1 and 2 cells with multiplication of a very small contaminating inoculum of Type 3 and 4 cells.

This medium seems quite unsuitable for the culture of Type 1 and Type 2 organisms.

\section{(2) Defined medium}

Kenny and others (1967) found this medium to give a good yield. They also reported that when inocula of phase (type) 1 colonies were employed, subsequent subcultures 'yielded only phase 1 colonies'. The present findings differ to some extent.

High initial counts of all colony types (i.e. $>10^{6} \mathrm{CFU} / \mathrm{ml}$.) allow modest increases in numbers to take place immediately. Cells from Types 3 and 4 remain unaltered, but those from Types 1 and 2 change to Types 3 and 4-but not before some multiplication in their original types has occurred. If smaller starting concentrations are used (e.g. $10^{4} \mathrm{CFU} / \mathrm{ml}$.), there is usually a considerable delay before growth starts. Cells from Types 3 and 4 remain unchanged during this lag phase, but organisms from Type 1 and 2 colonies only begin to divide as the type changes to 3 or 4 . If this change 
fails to occur then no multiplication takes place.

Thus, while this medium can yield reasonable growth of defined colony types, much care with the inoculum size and incubation time is needed.

Cultures inoculated with organisms from Types 3 and 4 had log phase generation times of 100 minutes. This suggests that the medium is far inferior to the complex single-phase alternative and that the organisms do not adapt well to it. The cells of Type 3 and 4 colonies derived from Type 1 and 2 inocula, however, had much shorter generation times. This suggests that with the change of colony type metabolic changes also occur.

\section{(3) Biphasic medium}

A biphasic medium was used by Sparling (1966) who observed great stability with cells of strain F62 Type 1. Other strains were not so stable.

The biphasic medium used by Gerhardt and Hedén (1960) seems to 'protect' cultures allowing prolonged high counts, whereas with both previous media the count declined rapidly after the peak had been reached.

Good increases in all colony types occur over 18-24 hrs after lag periods of varying length. Cells from Types 3 and 4 show little change in type, and whilst strain differences exist, cells from colony types 1 and 2 are more stable in this than other media. However, changes in type of a proportion of these cells do still occur.

Thus it is confirmed that a biphasic medium gives the best chance of a good yield of cells that form colonies of unchanged type (Sparling, 1966).

\section{(4) $\mathrm{CO}_{2}$ tension and incubation temperature}

The results suggest that the highest $\mathrm{CO}_{2}$ tension which allows good growth of the gonococcal strain will be optimal for the maintenance of cells resulting in colonies of Types 1 and 2. This is in agreement with the observations of Kellogg and others (1963) that higher $\mathrm{CO}_{2}$ tensions favoured growth of Types 1 and 2 on solid media.

Alteration of the incubation temperature to $30^{\circ} \mathrm{C}$. appears to allow maximum type stability to cells from Type 2 colonies.

\section{Summary and conclusion}

Colony type stability and ultimate yield of gonococci in liquid batch cultures have been investigated and the effects of medium type, inoculum size, carbon dioxide tension, and incubation temperature observed.

Some degree of multiplication was obtained under most conditions. Cells when plated from cultures which had been inoculated with Type 3 or Type 4 colonies gave rise to colonies of the inoculum type, whereas cells plated from cultures inoculated with Type 1 or Type 2 colonies often gave rise to colonies of Type 3 or 4. Types 1 and 2 were more stable in biphasic media at higher $\mathrm{CO}_{2}$ tensions, and incubation at $30^{\circ} \mathrm{C}$. afforded the least variation of colony Type 2.

With the knowledge now available it should be possible to obtain large quantities of organisms in any desired colony type.

The author wishes to thank Dr. Alice Reyn for much helpful advice at all stages in the production of this manuscript and Miss Anne-Gretë Overgaard for producing the figures.

\section{References}

Brookes, R., and Hedén, C. -G. (1967) Appl. Microbiol., 15, 219

Gerhardt, P., and Hedén, C. -G. (1960) Proc. Soc. exp. Biol. (N.Y.), 105, 49

JephCott, A. E., and ReYN, A. (1971) Acta path. microbiol. scand., Section B, 79, 609

Kellogg, D. S., Jr., Peacock, W. L., Deacon, W. E., Brown, L., and PIRKLE, C. I. (1963) f. Bact., 85, 1274

KenNy, C. P., Ashton, F. E., Diena, B. B., and GreenBERG, L. (1967) Bull. Wld Hlth Org., 37, 569

Morgan, J. F., Morton, H. J., and PARKeR, R. C. (1950) Proc. Soc. exp. Biol. (N.Y.), 73, 1

Møller, V. and ReYN, A. (1965) Bull. Wld Hlth Org., 32, 471

Reyn, A. (1971) Personal communication

Sparing, P. F. (1966) f. Bact., 92, 1364

Étude préliminaire de la stabilité des types de Neisseria gonorrhoeae dans les cultures en milieu liquide

\section{SOMMAIRE}

La stabilité des types de colonies de gonocoques et les caractéristiques des germes obtenus in fine dans des lots de cultures liquides ont été étudiées pour observer les effets du type de milieu, de l'importance de l'inoculum, de la tension en $\mathrm{CO}_{2}$ et de la température d'incubation.

Dans la majorité des conditions, on obtint un certain degré de multiplication. En cultivant sur plaques les éléments provenant des cultures inoculées avec le type 3 ou le type 4, on obtint des colonies correspondant au type de l'inoculum, alors que les plaques ayant reçu des cultures inoculées avec le type 1 ou le type 2 donnaient souvent des colonies de type 3 ou 4. Les types 1 et 2 furent plus stables dans les milieux biphasiques aux plus hautes concentrations en $\mathrm{CO}_{2}$ et, pour les colonies de type 2 , c'est l'incubation à $30^{\circ} \mathrm{C}$. qui entraîna le moins de variations.

Grâce à ce que l'on connaît maintenant, il doit être possible d'obtenir de grandes quantités d'organismes de n'importe quel type de colonie désirée. 